\title{
WINOGRADSKY REVIEW
}

\section{Microbial ecology meets electrochemistry: electricity-driven and driving communities}

\author{
Korneel Rabaey ${ }^{1,2}$, Jorge Rodríguez ${ }^{1}$, Linda L Blackall ${ }^{1}$, Jurg Keller ${ }^{1}$, Pamela Gross ${ }^{3}$, \\ Damien Batstone ${ }^{1}$, Willy Verstraete ${ }^{2}$ and Kenneth H Nealson ${ }^{4}$ \\ ${ }^{1}$ The Advanced Wastewater Management Centre, University of Queensland, Brisbane, Queensland, \\ Australia; ${ }^{2}$ Laboratory of Microbial Ecology and Technology (LabMET), University of Ghent, Ghent, Belgium; \\ ${ }^{3}$ School of Medicine, University of Southern California, Los Angeles, CA, USA and ${ }^{4}$ Department of Earth \\ Sciences, University of Southern California, Los Angeles, CA, USA
}

\begin{abstract}
Bio-electrochemical systems (BESs) have recently emerged as an exciting technology. In a BES, bacteria interact with electrodes using electrons, which are either removed or supplied through an electrical circuit. The most-described type of BES is microbial fuel cells (MFCs), in which useful power is generated from electron donors as, for example, present in wastewater. This form of charge transport, known as extracellular electron transfer, was previously extensively described with respect to metals such as iron and manganese. The importance of these interactions in global biogeochemical cycles is essentially undisputed. A wide variety of bacteria can participate in extracellular electron transfer, and this phenomenon is far more widespread than previously thought. The use of BESs in diverse research projects is helping elucidate the mechanism by which bacteria shuttle electrons externally. New forms of interactions between bacteria have been discovered demonstrating how multiple populations within microbial communities can co-operate to achieve energy generation. New environmental processes that were difficult to observe or study previously can now be simulated and improved via BESs. Whereas pure culture studies make up the majority of the studies performed thus far, even greater contributions of BESs are expected to occur in natural environments and with mixed microbial communities. Owing to their versatility, unmatched level of control and capacity to sustain novel processes, BESs might well serve as the foundation of a new environmental biotechnology. While highlighting some of the major breakthroughs and addressing only recently obtained data, this review points out that despite rapid progress, many questions remain unanswered.

The ISME Journal (2007) 1, 9-18; doi:10.1038/ismej.2007.4
\end{abstract}

Keywords: microbial fuel cell; extracellular electron transfer; bioremediation; wastewater treatment; nutrient removal

\section{From extracellular electron transfer to bio-electrochemical systems}

A bio-electrochemical system (BES) mimics bacterial interactions with insoluble electron donors and acceptors (Figure 1). In BES, bacteria need to establish an electrical link with this insoluble electron donor or acceptor. The most extensively described BES is the microbial fuel cell (MFC). In an MFC, bacteria oxidize an electron donor, with an anodic electrode as the electron acceptor. The electrons flow from the anode through an electrical circuit toward a high redox electron acceptor, such as oxygen, at the cathode. Cations make up the charge balance by diffusing from anode to cathode

Correspondence: Dr K Rabaey, The Advanced Wastewater Management Centre, Gehrmann Building (60), The University of Queensland, Brisbane, Queensland 4072, Australia.

E-mail: k.rabaey@uq.edu.au

Received 19 February 2007; accepted 21 February 2007 through a charge-selective separator (Rabaey and Verstraete, 2005). In addition, bacteria can consume electrons at the cathode with the reduction of electrochemically positive electron acceptors such as nitrate, perchlorate or metals (Gregory et al., 2004; Gregory and Lovley, 2005; Clauwaert et al., 2007; Thrash et al., 2007).

The underlying driver in all anodic and cathodic cases is extracellular electron transfer. Extracellular electron transfer is required whenever an electron acceptor or donor cannot enter the cell. Extracellular electron transfer has primarily been studied in microorganisms that transfer electrons to insoluble Fe(III) or Mn(IV) oxides or to humic substances that are too large to enter cells (Lovley et al., 1987, 1996; Myers and Nealson, 1988). Whereas similar principles may apply to microbe-electrode interactions (Rabaey and Verstraete, 2005; Lovley, 2006), the mechanisms of extracellular electron transfer, and the overall impact on microbial ecology and physiology, are poorly understood. 


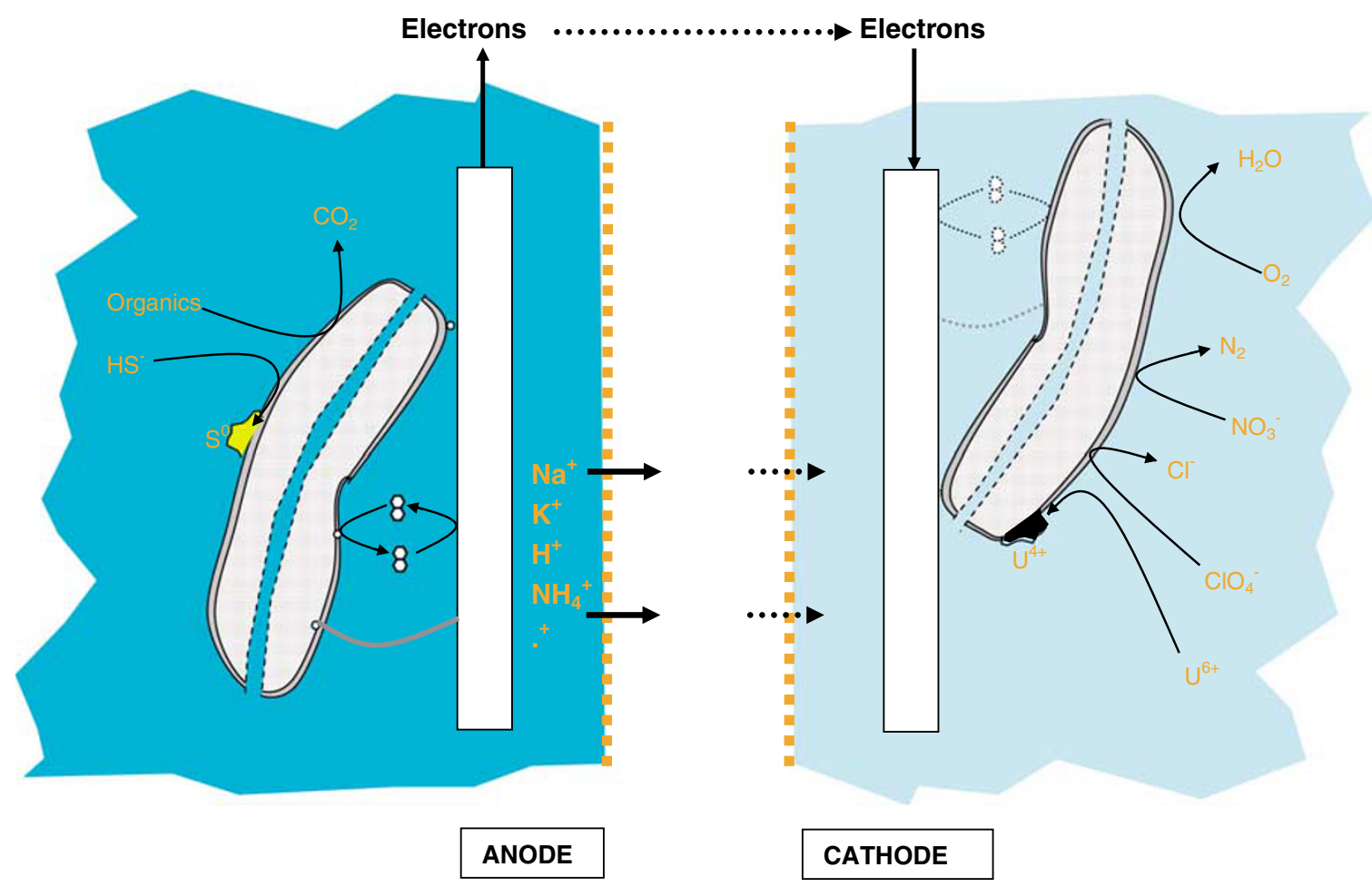

Figure 1 Schematic representation of possible reactions occurring at biologically catalyzed anodes and cathodes. At the anode, electrons are gained through the oxidation of organic electron donors (Rao et al., 1976) or possibly also sulfide oxidation (Rabaey et al., 2006). The electrons can be conveyed to the anode by either direct or indirect electron transfer. At the cathode, the mode through which electrons are conveyed to the bacteria has not been studied so far, the depicted pathways are therefore assumed. Oxygen (Bergel et al., 2005), nitrate (Clauwaert et al., 2007), hexavalent uranium (Gregory and Lovley, 2005) and perchlorate have been reduced at bio-cathodes so far. It must be noted that hydrogen is a possible electron shuttle at the cathode in case the potential of the cathode is poised at strongly negative values. When an anode and a cathode are combined, and at least one of the compartments is employing bacteria as catalysts, a BES is formed.

The bacterial cell yield depends on the potential difference between the electron donor and acceptor, which translates into the energy available for the bacteria (Heijnen, 1999). The potential difference between donor and acceptor is calculated with the Nernst equation as a dependent of the amount of oxidized and reduced compound present (Rabaey and Verstraete, 2005). In BES anodes, the potential of the electron acceptor is defined by the anodic potential, whereas in BES cathodes, the cathodic electrode determines the electron-donor potential. However, the bacteria cannot always fully exploit the actual potential of, e.g., the electron acceptor in BES anodes, as losses occur between the bacteria and the electrodes. These losses can be described as activation losses and electrolyte-resistance losses (Larminie and Dicks, 2000). The resistance of the electrolyte causes a distant dependent loss. Thus, the closer the interaction between bacteria and the electrode, the lower this loss. Activation losses are intrinsic to oxidation/reduction reactions and are less straightforward to describe (Logan et al., 2006). They reflect the losses resulting from the imperfect catalysis of oxidation/reduction reaction. The activation loss at an electrode, or toward or away from an insoluble electron acceptor/donor, respectively, can be described by the Butler-Volmer equation (Bard and Faulkner, 2001). The parameters of this equation can be determined through a linearization, after which the gain for bacteria can be calculated based on an electron flux. The result of such a measurement can be seen in Figure 2. The electrode/ biofilm combination can cope with far larger current densities without showing substantial potential losses. This demonstrates that the electrode/biofilm combination has become a far better catalyst than the electrode alone. Clearly, bacteria improve (electrochemical) catalysis. However, these measurements do not disclose the method through which bacteria operate.

\section{How do bacteria function in a BES?}

Bacteria become, from an electrochemical point of view, better catalysts by facilitating electron transport between the electron donor and the electrode. Thus far, primarily anodic processes have been studied with respect to electron transfer mechanisms. Whereas the reductions of Fe(III) and Mn(IV) oxides and anodes appear highly similar, distinct differences indicate that not only the redox potential 


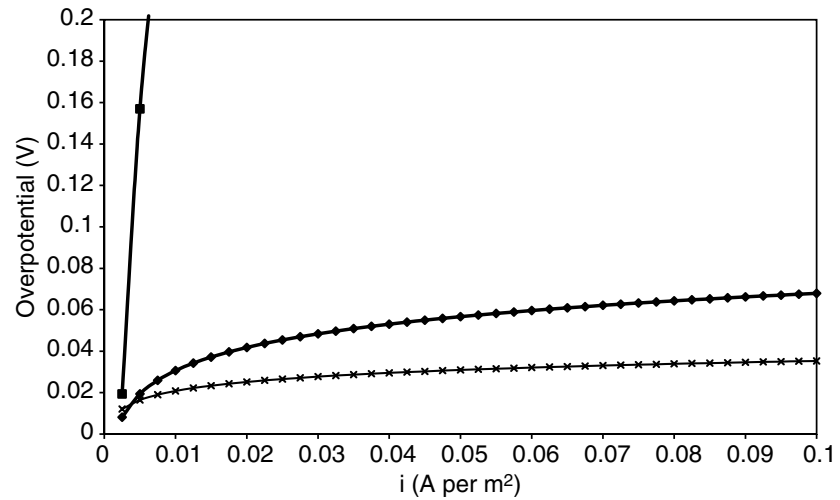

Figure 2 How bacteria make a difference... the exchange of electrons to and from electrodes requires a certain activation energy, which translates into a potential loss (V). The larger the current flowing between the medium and the electrode, the larger this potential loss. The addition of a catalyst lowers the activation energy, and therefore, also the potential losses. Without bacteria ( $\boldsymbol{\square})$ or other catalysts, even at low current densities, the potential loss quickly becomes substantial at an anode, whereas in the presence of bacteria $(x)$, the same electrode shows excellent electrochemical properties. The bacteria growing on the anode outperform a well catalyzed ferricyanide utilizing cathode $(\diamond)$. The measurements and subsequent calculations were performed using a system according to Aelterman et al. (2006) and the Butler-Volmer equation (Larminie and Dicks, 2000).

determines the utilization rate and strategy. At present, bacteria are assumed to either transfer electrons through immobilized structures or mobile components.

\section{Electron transfer through immobilized structures}

Some microorganisms must establish a direct contact with insoluble electron acceptors in order to promote electron transfer (Bond and Lovley, 2003). This has been demonstrated extensively for $\mathrm{Geo}$ bacter species, where electron transfer to $\mathrm{Fe}(\mathrm{III})$ oxides requires the presence of several outermembrane $c$-type cytochromes (Leang et al., 2005; Mehta et al., 2005) and other outer-membrane proteins (Afkar et al., 2005; Mehta et al., 2005). For soluble electron acceptors, such as Fe(III) citrate, this is not the case. Without direct contact, Geobacter spp. cannot reduce Fe(III) oxides. More recently, it was noted that outer-membrane proteins are not always sufficient for the reduction of Fe(III) oxides. For Geobacter sulfurreducens, the reduction requires pili, also referred to as nanowires, which are specifically produced during growth on ferric oxide, but not observed during growth on soluble electron acceptors (Childers et al., 2002; Reguera et al., 2005). In addition to pili, Geobacter metallireducens also synthesizes flagella when grown with $\mathrm{Fe}(\mathrm{III})$ oxides as electron acceptor (Childers et al., 2002). However, as the chemotaxis of this organism is toward Fe(II), and not Fe(III), it is as yet unclear whether synthesis of the flagella is relevant to establishing contact with an electrode, as electrodes do not release reduced reaction products such as $\mathrm{Fe}(\mathrm{II})$.

Likewise, Shewanella oneidensis MR-1 produces pilus-like structural components (Gorby et al., 2006). In this case, contrary to Geobacter species, the nanowires are arrayed in larger bundles, often reaching $50 \mathrm{~nm}$ in diameter, and extending many micrometers from the producing cell. Experiments with gold-labeled antibodies have shown that these highly conductive nanowires are decorated with surface proteins, including some of the major decaheme proteins generally involved in iron reduction (Gorby et al., 2006). Bacterial cells containing deletion mutations in the pilD gene do not produce nanowires, and are incapable of electricity production or the reduction of Fe(III) oxide (Bretschger and Nealson, unpublished results). These cells are still capable of reducing the soluble (Fe(III)NTA) to ferrous iron. Deletion mutations in the mtrC/omcA gene complex result in cells that produce nanowires that are easily visible, but which appear to be non-conductive based upon scanning tunneling microscopy. Gorby et al. (2006) noted that electrically conductive pilus-like appendages were produced by several bacteria besides $S$. oneidensis when grown with ferrihydrite as electron acceptor. $S$. oneidensis MR-1 also required several $c$-type cytochromes to create the conductive link between the bacteria and the insoluble electron acceptor.

The findings that both Shewanella and Geobacter species can employ similar strategies indicate that the combination of cytochromes and conductive nanowires is a general strategy for extracellular electron transfer toward Fe(III) oxides, in addition to the further-described shuttling mechanisms. The similarities and dissimilarities between nanowires produced by Shewanella and Geobacter spp., and other bacterial species in general, are still the subject of debate. As observed for metal reduction, both cytochromes and pili appear to be involved in current production by Geobacter and Shewanella. The relative importance of both factors can shift, however, depending on whether the bacteria actually form a biofilm or grow in monolayers.

Expression of the gene for the outer-membrane $c$-type cytochrome, OmcS, was much higher in fuel cells of Geobacter growing as monolayers on the anode compared with Geobacter grown in suspension on a soluble electron acceptor (Holmes et al., 2006). Deleting the gene for OmcS inhibited power production, whereas current was restored when the gene was reintroduced. This result suggests that OmcS can be an electrical contact between the cell and the anode. Geobacter can also form thick $(>50 \mu \mathrm{m})$ biofilms on electrodes (Reguera et al., 2006a). Cells at a distance to the anode had similar viability as compared to cells adjacent to the anode. Under these conditions, pili production is essential for optimum current production (Reguera et al., 2006a). It remains to be determined whether the microbial nanowires must directly contact the anode 
or whether cell-to-cell electron transfer through the biofilm is possible. The pili may also provide structural support in biofilm formation (Reguera et al., 2006b).

Direct electron transport is possibly bidirectional, as Geobacter species have been shown to accept electrons from a cathode (Gregory et al., 2004). Also, denitrifying biofilms have been developed on cathodes (Clauwaert et al., 2007), but the mechanism of such bacterially driven transfer has not been elucidated.

\section{Electron transfer through mobile components}

Alternatively, bacteria can produce and use soluble components known as redox shuttles or redox mediators. The most extensively described examples in BESs are phenazines such as pyocyanin and phenazine-1-carboxamide, which are redox-active compounds produced by Pseudomonas species (Hernandez et al., 2004; Rabaey et al., 2005a). These compounds were essential for current generation by Pseudomonas aeruginosa KRP1, an isolate from an MFC. There are several studies on the role of humic acids as redox shuttles in ferric iron reduction (Lovley et al., 1996, 2004), but so far none have focused on the role humics play in BES. Recently, Milliken and May (2007) used humics to obtain extracellular electron transfer by Desulfitobacterium hafniense. This indicates that in sediment-based BESs, where humics are often present, they could function as redox shuttles.

Shewanella putrefaciens is capable of using externally provided electron shuttles, such as the humic acid model compound anthraquinone-2,6disulfonic acid (AQDS), but whether the organism is capable of obtaining shuttle-based electron transfer by synthesizing a shuttle is still a subject of debate (Newman and Kolter, 2000). Also Geobacter species have the capacity to utilize redox shuttles when these are provided externally. For example, when physically separated from their electron acceptor, Geobacter metallireducens was capable of reducing $\mathrm{Fe}(\mathrm{III})$ oxides when AQDS was added to the medium (Nevin and Lovley, 2000).

The number of possible electron shuttles is surprisingly large. In addition to organic heterocyclic and monocyclic compounds, sulfur species and hydrogen can be used as electron shuttles (Lovley, 2000; Straub and Schink, 2004; Niessen et al., 2005; Rabaey et al., 2006). To mimic the microbial shuttling, redox-active compounds such as neutral red can be added to the anode compartment of an MFC (Park and Zeikus, 2000). In one study, it was shown that Escherichia coli species transported neutral red into the periplasmic space, where a hydrogenase-mediated reduction occurred (McKinlay and Zeikus, 2004). Hydrogenases appear to be involved in linking the electrons passing through the inner membrane to further electron transfer, which is also corroborated by the fact that the genes coding for these enzymes are upregulated during growth on insoluble electron acceptors (Holmes et al., 2006).

The critical issue with mediated electron transfer is the diffusion of the shuttle out of the biofilm or the bacterial environment. As the energy investment to produce shuttles is considerable, this efflux can render the shuttling process thermodynamically inefficient (Childers et al., 2002) or at least less favorable than direct transfer as used by Geobacter species (Madahevan et al., 2006). Whereas, initially, shuttling was only found in systems where the bulk liquid was only irregularly replaced (Rabaey et al., 2004; Bond and Lovley, 2005), bacteria capable of producing redox shuttles have also been found in continuous-flow MFC, where the bulk liquid is continuously replaced (Aelterman et al., 2006). Redox shuttles appear to be present mainly in the biofilm, and not in the bulk liquid (Bond and Lovley, 2005), but the underlying mechanism for this selective presence has yet to be addressed. As the calculations in the Supplementary data indicate (see Supplementary Figures 1-4), electrostatic interactions may play a big role in redox shuttling. Based on the Nernst-Planck equation (MacGillivray, 1968), one can calculate that for phenazine-1-carboxamide - a well-described redox shuttle - the flux of its reduced form through a biofilm toward a modeled anode is substantially accelerated (in the calculated case) by the electrostatic attraction (Supplementary data S1), whereas the efflux of its oxidized form is determined by concentration gradients. This enhances the retention of shuttles in a biofilm by more than an order of magnitude in comparison to conventional diffusion models, which results in a substantial difference in current stability (Supplementary Figure S1) and redox potential evolution (Supplementary Figure S2), even without the inclusion of a shuttle production term in the used model. Nearly all the shuttles would theoretically accumulate close to the anode (Supplementary Figure S3), whereas the shuttle concentration at the top of the biofilm is almost negligible in comparison (Supplementary Figure S4). This could create a duality between bacteria at the bottom of the biofilm, which have direct access to electron acceptors but are limited in electron donor availability, and bacteria at the top of the biofilm, which have direct access to the electron donor but are limited in electron acceptor availability. Experimental validation is needed to confirm this effect in situ, and investigate its ecological implications.

\section{Gram-positive electron shuttling}

Perhaps unexpectedly, Gram-positive bacteria were found to play a role in MFC. Their presence appears to be an outcome of an ecological interaction rather than a direct involvement. Isolates of Enterococcus (Rabaey et al., 2004, 2005a) and Brevibacillus (Pham 
Box 1 Finding out: using bio-electrochemical systems (BESs) to study microbial dynamics and microbial ecology

BESs are increasingly used to study the microbial mechanisms of electron transfer. As BESs offer a plethora of options to monitor and/ or control bacterial activity in different redox or flux conditions, the capacities are only beginning to be exploited. The basic strategies include the following:

- Electrode potential control: The electrode potential is controlled at a fixed level, at which the current density can be monitored as an indicator for bacterial activity. This approach targets certain metabolic patterns. The electrode potential can be varied to shift from oxidation to fermentation of a substrate. For example, a glucose-fed microbial fuel cell (MFC) had an order of magnitude more acetate in the effluent when the external resistance was 100 vs $20 \Omega$, with resulting anodic potentials of about -250 and $0 \mathrm{mV}$ vs standard hydrogen electrode (SHE), respectively (Stefano Freguia, available online). This type of control has extensively been used for MFC research (Bond and Lovley, 2003; Rabaey et al., 2006). The colonization rate and growth yield of the bacteria changed as a function of the applied potential (Finkelstein et al., 2006), thus providing a system to examine how small changes in potential impact bacterial communities.

- Bacterial activity control: A fixed current is demanded of, or provided to, a biological system, which can stimulate or decelerate a process. Depending on the capability of the system to deliver this current, the potential of the electrode will evolve (Larminie and Dicks, 2000). When a certain current is demanded from bacteria, and they can indeed deliver the electrons, then the potential will remain within the normal redox boundaries for the bacteria. A decrease in anode potential indicates enrichment, as the bacteria generate more reduced conditions (Rabaey et al., 2004). This would enable a higher current demand. An increase of the potential beyond the normal biological boundaries indicates inability of the bacteria to provide electrons at a sufficient rate to avoid electrochemical oxidation of solutes. Electrode surface increase and catalysis (Park and Zeikus, 2003) or mediator addition (Roller et al., 1984) would be the necessary modifications to improve this situation. The reverse process can also be envisaged at a cathode. If bacteria at a cathode are unable to take up the electrons delivered, electrochemical processes such as hydrogen generation can occur. This production has already been proposed as an abiotic hydrogen generation strategy (Liu et al., 2005; Rozendal et al., 2006).

- Bacterial potential control: When working with a fixed external resistance, the evolution of the electrode's potential as a function of bacterial kinetics can be monitored. In this case, bacteria will drive the system toward an attainable activity that allows energy capture for growth and maintenance (Freguia et al., 2007). Communities adapt quickly to large fluctuations in the potential of the electron acceptor, as decreases of up to $500 \mathrm{mV}$ of the anode potential in an MFC have been observed within just a few hours (Rabaey et al., 2004, 2005b). Also for cathodic processes, variable potentials can be observed, for example, as a function of nitrate loading rate and applied external resistor (Clauwaert et al., 2007).

An important factor in BES research will be 'electrochemical quality' of the reactor. Indeed, factors such as internal resistance, electrode surface and mixing will determine the accuracy of measurements, the attainable substrate fluxes and the accumulation of intermediates and end products.

et al., unpublished results) spp. produced very low current when grown in pure culture with acetate as the electron donor. The latter organism was one of the dominant species in a microbial consortium enriched in an MFC fed with acetate (Aelterman et al., 2006). When this pure culture was combined with Pseudomonas sp. or supernatant obtained from an MFC containing Pseudomonas sp., the current generation increased. Recently, Milliken and May (2007) described a similar interaction with Desulfitobacterium hafniense. In this case, humic acids were used as the electron shuttle. However, the current generation could not be sustained in most cases, indicating that the presence of humics is insufficient to drive the electron shuttling by Desulfitobacterium species. Further research should be directed at investigating the true role of Gram positives in BESs and in electron acceptor-limited sedimentary systems (Box 1).

\section{BES and microbial ecology in the natural environment}

In MFCs, biofilms performing extracellular electron transfer are almost always present and can reach considerable thickness (Reguera et al., 2006a). The bacteria in these biofilms typically develop a plurality of electron transfer strategies (Rabaey et al., 2004). Electrochemically competent complex and diverse microbial communities develop in reactor type MFCs when operated over a long time period. Figure 3 (Aelterman et al., 2006) demonstrates how a microbial community can overcome both diffusion limitations and activity limitations over time. Diffusion limitations, referred to as concentration polarization in BESs, lead to a decrease in current observed during the recording of a polarization curve. The long-term disappearance of this effect implies that the bacterial biofilm either solved the diffusion limitation on the influx of substrate, or solved the limitations in discharging electrons to the electrode. At the point of maximal power (Figure 3), the microbial community was dominated by a Gram-positive bacterium unable to generate current when grown alone (Aelterman et al., 2006; Pham et al., unpublished results). This demonstrates that microbial interactions can drive the community succession toward an electrochemically competent BES biofilm. The underlying mechanisms for this process, and how diffusion limitations for electron donors and acceptors are solved by bacteria, are as yet poorly understood.

For sedimentary systems, the role and function of nanowires and redox shuttles are also still unresolved. Sediment MFCs can be applied in more natural conditions than reactor-based MFCs, do develop biofilms, but generally show lower output 


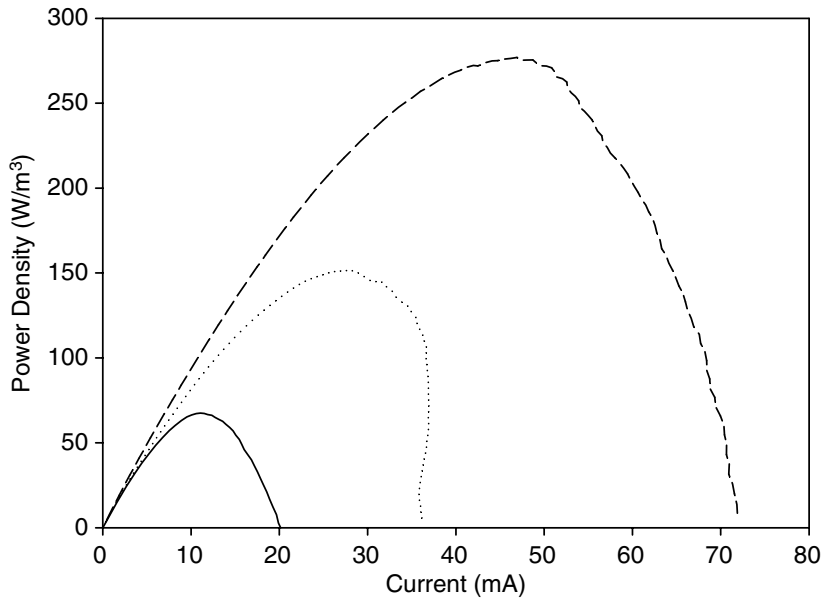

Figure 3 Polarization curves for a stacked MFC system, after Aelterman et al. (2006). In a polarization curve, the relationship between power generation by the MFC and current generation, which directly links to extracellular electron transfer, is examined. There is an optimal current - power that is reflected by the maximum in the curve (Logan et al., 2006). In the period after the start-up (full line), when the bacterial density is still low, the maximum power is limited. At time 2 (dotted line), the attainable power was higher, which indicates a maturation of the system, but adverse effects exist at higher currents caused by concentration polarization (seen by the non-parabolic part of the polarization curve at time 1). At time 3 (dashed line), even though the attainable power and current are substantially higher, this concentration polarization was no longer noted. This demonstrates that bacteria can create electrochemically competent biofilms over time, capable of solving diffusional and electrochemical limitations. Further research on how communities achieve this is certainly needed.

than their reactor counterparts (Ryckelynck et al., 2005). This may be caused by limitations on the substrate influx and the electron acceptor availability, as well as diffusion-based limitations (Ryckelynck et al., 2005).

Geobacter species are found in abundance in some sedimentary systems, in particular those that are continuously anaerobic and driven by acetate as a carbon source. This, may stem from their ability to gain an energetic advantage through direct electron transfer vs shuttle-assisted transfer (Madahevan et al., 2006). However, as indicated before, niches where large potential gradients exist, owing to diffusion limitations, may accommodate shuttleusing organisms that take advantage of the electrostatic attraction the electron acceptor exerts on the shuttle. From an ecological point of view, the most interesting aspect of redox shuttles is the absence of host specificity. Sediments and soils generally contain numerous compounds, including different humic acids that can serve as electron shuttles. Any bacterium capable of reducing the shuttle could potentially exploit the system (Rabaey et al., 2005a). This could imply that the opportunities for nonadapted species to survive in sedimentary systems are higher than predicted based on their own metabolic potential. As some of the assumed redox shuttles have midpoint potentials well above
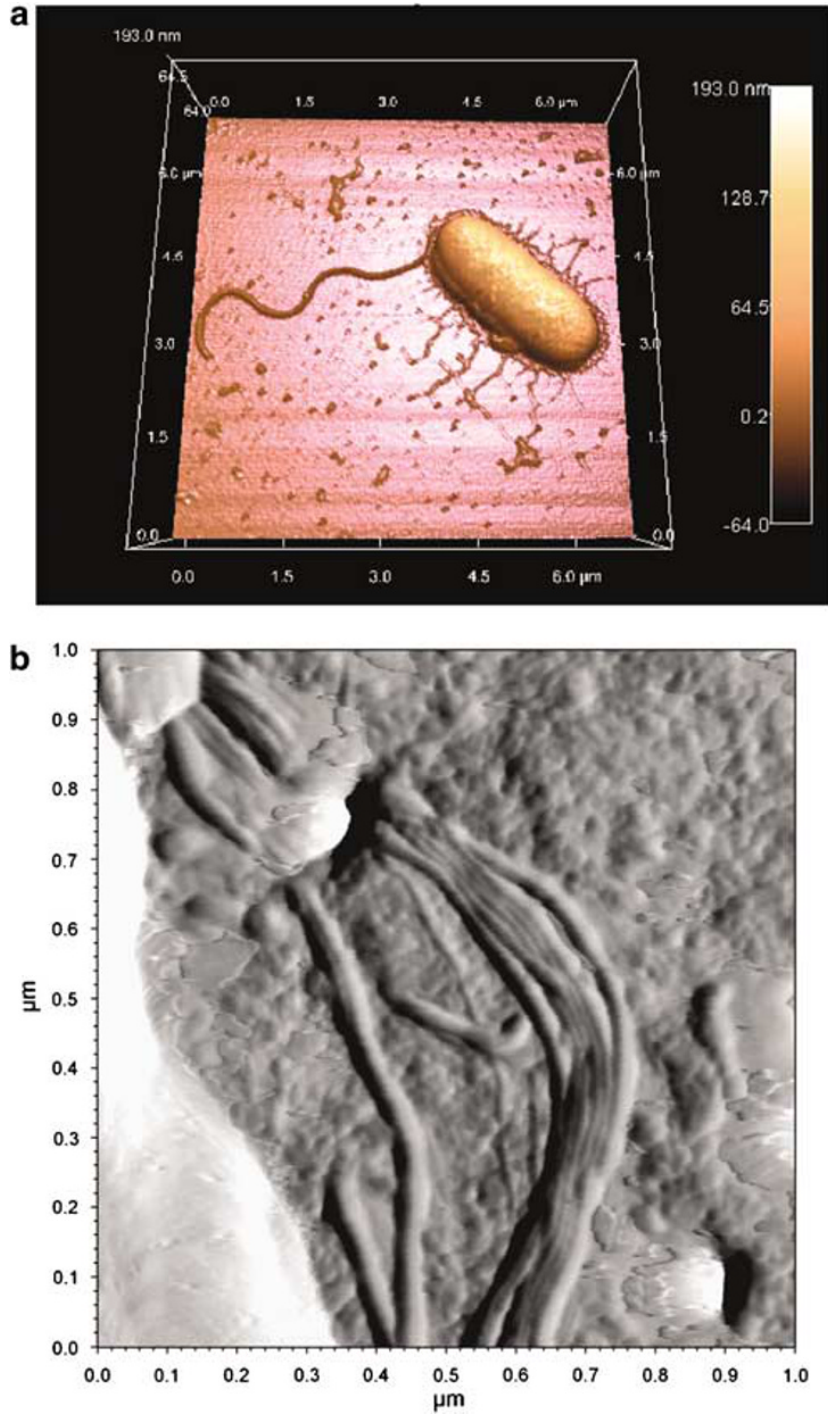

Figure 4 Images of $S$. oneidensis MR-1 grown in electron acceptor limited conditions. (a) Three-dimensional rendering of $S$. oneidensis MR-1 washed in suspension with water, then transferred to mica surface. A pattern of dried proteins and/or polysaccharides surrounds the bacteria on the substrate, and possible pili are seen extending from this pattern. Section analysis of the perpendicular structures extending from the edge of the bacteria reveals a height of $1.0-1.5 \mathrm{~nm}$, and a flagellar height of $8.4 \mathrm{~nm}$. (b) Atomic force microscope image of the amplitude data of a $1 \mu \mathrm{m}$ scan of the edge of a community of $S$. oneidensis MR-1 growing on a polycarbonate filter membrane. Distinct individual filaments are seen bundling together and then diving into a pore in the membrane. These bundles are highly conductive. The bundle width is $87 \mathrm{~nm}$ at its narrowest point, the bundle height is $5.5 \mathrm{~nm}$, and the individual filament height is $2.5-3.5 \mathrm{~nm}$.

$-150 \mathrm{mV}$ vs standard hydrogen electrode (SHE), the presence of shuttles allows for a substantial metabolic gain.

In batch experiments for the reduction of $\mathrm{Fe}(\mathrm{III})$ oxides, certain bacteria require the production of nanowires in order to reduce the Fe(III) oxides. The nanowires in Shewanella are produced in abundance under conditions of severe electron acceptor 
limitation (Gorby et al., 2006; Figure 4). One example of a niche in which nanowires might play a role is that of sediments rich in iron-rich clays. In such clays, substantial reduction of interlayer iron is observed (Kostka et al., 1996, 1999). This process could be carried out via electron shuttles, by the use of some iron-binding compounds like siderophores to transport the iron out of the clays, or perhaps by nanowires.

\section{From extracellular electron transfer to environmental biotechnology}

The findings through MFC/BES-based research have demonstrated that the capacity for extracellular electron transfer is widespread. Several strategies for extracellular electron transfer have been more clearly outlined, some of which are activated through interactions between bacteria. Insoluble electron acceptor-oriented foodwebs, starting from glucose (Rabaey et al., 2003) and starch (Niessen et al., 2004) to complex compounds such as nitrophenol and wastewater, can be constructed. The processes occurring can be categorized as oxidative or reductive.

\section{Oxidative processes}

Energy generation has been the prime objective of MFC/BES research thus far. MFCs have mainly been applied to soluble waste streams with low to medium loading, targeting recoveries of at least $1 \mathrm{kWh}$ of useable electricity per kilogram of organic matter removed, and generation of up to $1 \mathrm{~kW} / \mathrm{m}^{3}$ reactor volume. The sustained and reproducible exploitation of this energy will require better understanding and careful management of the microbial communities in the BES in terms of biomass density per unit volume and specific activity of the biomass (Pham et al., 2006). The ability to reach usable electricity targets from wastewater will make MFC technology comparable to the standard procedure of anaerobic digestion to methane in terms of cost and environmental soundness. However, for maximal sustainability, BES should be considered complementary to, rather than competitive with, anaerobic digestion. There are several advantages of MFCs, which make the technology attractive:

- An oxidative process generates an effluent with mostly oxidized residual compounds rather than short-chain fatty acids or reduced sulfur compounds such as hydrogen sulfide (Rabaey et al., 2006).

- Low-strength wastewaters can be effectively treated, also at ambient temperatures (Rabaey et al., 2005b).

- Integrated nitrogen removal by cathode-driven denitrification has also been demonstrated (Clauwaert et al., 2007).

- Expensive cogeneration facilities are not required, which make application at smaller scales more feasible $(<500 \mathrm{~kW})$. In addition, it is possible to utilize streams with sulfur present; these would normally require a caustic scrubber.

It remains to be seen whether BESs will rise to the challenge of the wastewater complexity. Microbial communities capable of degrading complex compounds (aside from starch, Niessen et al., 2004) with the concomitant generation of electricity have not yet been described for reactor-based BES. Sedimentbased MFC have been operated over longer time periods, but the nature of the organics converted in those cases was not determined. Reactor-type MFCs fed with wastewater mainly convert rapidly biodegradable organic matter. The more recalcitrant material generally passes more or less unaltered through the system. This can be because of the short residence times (Rabaey et al., 2005b) and the slower conversion of compounds such as complex aromatics under anaerobic conditions (Madigan et al., 2000). It can also be assumed that sediment MFCs also target mainly the rapidly biodegradable fraction of the organic matter entering the sediment.

Particulate matter will also tend to decrease contact of the electron donor with the anode. Hence, hydrolysis and fermentation may occur in zones that are not able to rapidly deliver the electron to the acceptor site, which would enable the establishment of a microbial community that does not interact with insoluble electron acceptors. Further research is required to define how thick and dense a biofilm can become before the organisms in the upper layer 'disconnect' from the insoluble electron acceptor. Comparing activated sludge flocs with BES biofilm communities will provide highly interesting information on how both communities work and which are the ecological differences between biofilms and flocs when both tackle the same wastewater. Based on the specificity of microbial biochemistry, some niches in the environmental domain might also become of interest such as the proposed use of BESs, to enhance oxidation rates in constructed wetlands (De Schamphelaire et al., unpublished results) and the application of these systems to bring about specific oxidative removal of sulfur compounds (Rabaey et al., 2006).

\section{Reductive processes}

Whereas oxidation processes have been extensively studied in MFC, reduction processes have barely been addressed. There may well be tremendous potential to develop novel biotechnological applications using cathodic reduction. Some examples are presented here, and additional examples have recently been reviewed (He and Angenent, 2006).

Denitrification. The main focus of BES treating wastewater has been on the reuse of water and the conversion of organic matter into electricity. The use of BES for nutrient management opens new per- 
spectives for an integrated and sustainable wastewater treatment process. At present, nitrogen is removed from wastewater by nitrification and denitrification. Enormous recycling of wastewater is required to satisfy the conflicting electron donor and acceptor requirements of nitrifiers and denitrifiers. This is highly energy demanding, and the process often requires the addition of electron donors. Gregory et al. (2004) enriched a graphite cathodic electrode that can deliver electrons directly to microorganisms for nitrate-to-nitrite reduction without $\mathrm{H}_{2}$ as an intermediate. Recently, complete denitrification with a so-called biocathode (He and Angenent, 2006) was described at a rate of $0.146 \mathrm{~kg} \mathrm{NO}_{3}^{-}-\mathrm{Nm}^{-3}$ cathodic liquid volume $\mathrm{d}^{-1}$ (Clauwaert et al., 2007). Neither a power supply nor a potentiostat were needed as a biological acetate-oxidizing anode delivered electrons to the cathodic electrode. An external resistance harvested electricity up to $0.017 \mathrm{kWh} \mathrm{mol}^{-1}$ electrons whereas $\mathrm{H}_{2}$ producing cathodes consume up to $1 \mathrm{kWh} \mathrm{mol}^{-1}$ electrons (Sakakibara and Kuroda, 1993). Denitrification only occurred when the redox potential of the cathodic electrode was below $0 \mathrm{~V}$ vs SHE. However, the mechanism by which the bacteria transfer electrons from an inert electrode into their electron transport chain to produce ATP remains unknown.

BESs for metal contaminant removal. The biological removal of metals can occur by oxidative and a reductive processes. One reported process used an electrode as electron donor for the microbial reduction of uranium (Gregory and Lovley, 2005). This caused the conversion of soluble U(VI) to the rather insoluble U(IV), which precipitated onto the electrodes. A major contribution of BES-based processes could be in the removal of a wide variety of heavy metals, thus addressing pollution by aqueous streams containing these contaminants.

With respect to freshwater bodies such as rivers, BESs might be of great value in preventing shock remobilization of sediments. Owing to increasing water quality, the oxygen availability in sediments is increasing, and in a cascade effect, this could cause remobilization of metals associated with, for example, sulfides (Salomons et al., 1987). Controlling the potential of the sediment may aid in a more gradual oxidation of sulfide species and, therefore, slower metal release. Further research will be needed to demonstrate the mode of implementation and the feasibility of such strategies.

Perchlorate removal. Recently, also the reduction of perchlorate in the cathode compartment of a BES was described. Thrash et al. (2007) were able to isolate one of the organisms responsible for the perchlorate reduction, which was designated strain VDY. When the cathode potential was poised at $-500 \mathrm{mV}$ vs $\mathrm{Ag} / \mathrm{AgCl}$ reference, the organism was capable of reducing perchlorate without the addi- tion of a redox mediator. Hydrogen, formed electrocatalytically at the cathode, likely served as the redox shuttle to convey the electrons toward strain VDY.

\section{Conclusions}

The knowledge of how bacteria interact with insoluble electron donors and acceptors is rapidly increasing. There are still a number of issues unresolved, such as the role of pili/nanowires and electron shuttles in the natural environment. However, complementary findings by several research groups indicate that the mechanisms for extracellular electron transfer are widespread and likely conserved. In the near future, BESs will become an important tool in filling knowledge gaps in extracellular electron transfer by microorganisms. BESs allow a unique control mechanism on activity and redox potential in the bacterial environment. In the longer term, the bio-electrochemical approach will strongly facilitate advanced interpretation of biogeochemical cycles, and the influence of changing environmental and anthropogenic factors on the bacteria driving them.

BESs also offer a number of exciting prospects for novel biotechnological applications. The recent studies that demonstrate how nitrate, perchlorate, sulfur and other compounds can be adequately removed using BESs are the first indication of the feasibility of processes driven by extracellular electron transfer. However, there are still many hurdles ahead before BESs can compete with existing technologies and before we can fully exploit their capacity to drive sustainable processes.

\section{Acknowledgements}

We thank Derek Lovley for his valuable comments and inputs to this work. Also the useful remarks provided by Peter Clauwaert are greatly appreciated. Korneel Rabaey is supported through the Postdoctoral Fellow Scheme at the University of Queensland and through the Australian Research Council Discovery program. The Ncalson laboratory acknowledges the support from the AFOSR MURI program. LabMET acknowledges the support of FWO and IWT Vlaanderen.

\section{References}

Aelterman P, Rabaey K, The Pham H, Boon N, Verstraete W. (2006). Continuous electricity generation at high voltages and currents using stacked microbial fuel cells. Environ Sci Technol 40: 3388-3394.

Afkar E, Reguera G, Schiffer M, Lovley DR. (2005). A novel Geobacteraceae-specific outer membrane protein J (OmpJ) is essential for electron transport to Fe (III) and Mn (IV) oxides in Geobacter sulfurreducens. BMC Microbiology 5: Art. No. 41. 
Bard AJ, Faulkner LR. (2001). Electrochemical Methods: Fundamentals and Applications, 2nd edn. John Wiley \& Sons: New York.

Bergel A, Feron D, Mollica A. (2005). Catalysis of oxygen reduction in PEM fuel cell by seawater biofilm. Electrochem Comm 7: 900-904.

Bond DR, Lovley DR. (2003). Electricity production by Geobacter sulfurreducens attached to electrodes. Appl Environ Microbiol 69: 1548-1555.

Bond DR, Lovley DR. (2005). Evidence for involvement of an electron shuttle in electricity generation by geothrix fermentans. Appl Environ Microbiol 71: 2186-2189.

Childers SE, Ciufo S, Lovley DR. (2002). Geobacter metallireducens accesses insoluble $\mathrm{Fe}(\mathrm{III})$ oxide by chemotaxis. Nature 416: 767-769.

Clauwaert P, Rabaey K, Aelterman P, De Schamphelaire L, The Pham H, Boeckx $\mathrm{P}$ et al. (2007). Biological denitrification driven by microbial fuel cells. Environ Sci Technol (available online).

Finkelstein DA, Tender LM, Zeikus JG. (2006). Effect of electrode potential on electrode-reducing microbiota. Environ Sci Technol 40: 6990-6995.

Freguia S, Yuan S, Rabaey K, Keller J. (2007). Electron and carbon balances in microbial fuel cells reveal temporary bacterial storage behaviour during electricity generation. Environ Sci Technol (available online).

Gorby YA, Yanina S, McLean JS, Rosso KM, Moyles D, Dohnalkova A et al. (2006). Electrically conductive bacterial nanowires produced by Shewanella oneidensis strain MR-1 and other microorganisms. Proc Natl Acad Sci USA 103: 11358-11363.

Gregory KB, Bond DR, Lovley DR. (2004). Graphite electrodes as electron donors for anaerobic respiration. Environ Microbiol 6: 596-604.

Gregory KB, Lovley DR. (2005). Remediation and recovery of uranium from contaminated subsurface environments with electrodes. Environ Sci Technol 39: 8943-8947.

He Z, Angenent LT. (2006). Application of bacterial biocathodes in microbial fuel cells. Electroanalysis 18: 2009-2015.

Heijnen JJ. (1999). Bioenergetics of microbial growth. In: Flickinger MC, Drew SW (eds). Bioprocess Technology: Fermentation, Biocatalysis and Bioseparation. John Wiley \& Sons Inc.: New York, pp 267-291.

Hernandez ME, Kappler A, Newman DK. (2004). Phenazines and other redox-active antibiotics promote microbial mineral reduction. Appl Environ Microbiol 70: 921-928.

Holmes DE, Chaudhuri SK, Nevin KP, Mehta T, Methe BA, Liu A et al. (2006). Microarray and genetic analysis of electron transfer to electrodes in Geobacter sulfurreducens. Environ Microbiol 8: 1805-1815.

Kostka JE, Stucki JW, Nealson KH, Wu J. (1996). Reduction of structural Fe(III) in smectite by a pure culture of Shewanella putrefaciens strain MR-1. Clays Clay Min 44: 522-529.

Kostka JE, Wu J, Nealson KH, Stucki JW. (1999). The impact of structural Fe(III) reduction by bacteria on the surface chemistry of smectite clay minerals. Geochim Geochos Acta 63: 3705-3713.

Larminie J, Dicks A. (2000). Fuel Cell Systems Explained. John Wiley \& Sons: Chichester, 308pp.

Leang C, Adams LA, Chin KJ, Nevin KP, Methe BA, Webster J et al. (2005). Adaptation to disruption of the electron transfer pathway for $\mathrm{Fe}(\mathrm{III})$ reduction in Geobacter sulfurreducens. J Bacteriol 187: 5918-5926.
Liu H, Grot S, Logan BE. (2005). Electrochemically assisted microbial production of hydrogen from acetate. Environ Sci Technol 39: 4317-4320.

Logan B, Aelterman P, Hamelers B, Rozendal R, Schroder U, Keller J et al. (2006). Microbial fuel cells: methodology and technology. Environ Sci Technol 40: 5181-5192.

Lovley DR. (2000). Fe(III) and Mn(IV)-reducing prokaryotes. In: Dworkin M, Falkow S, Rosenberg E, Schleifer K, Stackebrandt E (eds). The Prokaryotes. Springer-Verlag: New York.

Lovley DR. (2006). Bug juice: harvesting electricity with microorganisms. Nat Rev Microbiol 4: 497-508.

Lovley DR, Coates JD, BluntHarris EL, Phillips EJP, Woodward JC. (1996). Humic substances as electron acceptors for microbial respiration. Nature 382: 445-448.

Lovley DR, Holmes DE, Nevin KP. (2004). Dissimilatory Fe(III) and Mn(IV) reduction. Adv Microb Physiol 49: 219-286.

Lovley DR, Stolz JF, Nord GL, Phillips EJP. (1987). Anaerobic production of magnetite by a dissimilatory iron-reducing microorganism. Nature 330: 252-254.

MacGillivray AD. (1968). Nernst-Planck equations and the electroneutrality and Donnan equilibrium assumptions. J Chem Phys 48: 2903-2907.

Madahevan R, Bond DR, Butler JE, Esteve-Nunez A, Coppi $\mathrm{M}$, Palsson BO et al. (2006). Characterization of metabolism in the Fe(III)-reducing organism Geobacter sulfurreducens by constraint-based modeling. Appl Environ Microbiol 72: 1558-1568.

Madigan MT, Martinko J, Parker J. (2000). Brock Biology of Microorganisms. Prentice-Hall: Englewood Cliffs, NJ, 991pp.

McKinlay JB, Zeikus JG. (2004). Extracellular iron reduction is mediated in part by neutral red and hydrogenase in Escherichia coli. Appl Environ Microbiol 70: 3467-3474.

Mehta T, Coppi MV, Childers SE, Lovley DR. (2005). Outer membrane $c$-type cytochromes required for $\mathrm{Fe}$ (III) and $\mathrm{Mn}(\mathrm{IV})$ oxide reduction in Geobacter sulfurreducens. Appl Environ Microbiol 71: 8634-8641.

Milliken CE, May HD. (2007). Sustained generation of electricity by the spore-forming, Gram-positive, Desulfitobacterium hafniense strain DCB2. Appl Microbiol Biotechnol 73: 1180-1189.

Myers CR, Nealson KH. (1988). Bacterial manganese reduction and growth with manganese oxide as the sole electron-acceptor. Science 240: 1319-1321.

Nevin KP, Lovley DR. (2000). Lack of production of electron-shuttling compounds or solubilization of Fe(III) during reduction of insoluble Fe(III) oxide by Geobacter metallireducens. Appl Environ Microbiol 66: 2248-2251.

Newman DK, Kolter R. (2000). A role for excreted quinones in extracellular electron transfer. Nature 405: 94-97.

Niessen J, Schroder U, Harnisch F, Scholz F. (2005). Gaining electricity from in situ oxidation of hydrogen produced by fermentative cellulose degradation. Lett Appl Microbiol 41: 286-290.

Niessen J, Schroder U, Scholz F. (2004). Exploiting complex carbohydrates for microbial electricity generation - a bacterial fuel cell operating on starch. Electrochem Comm 6: 955-958.

Park DH, Zeikus JG. (2000). Electricity generation in microbial fuel cells using neutral red as an electronophore. Appl Environ Microbiol 66: 1292-1297. 
Park DH, Zeikus JG. (2003). Improved fuel cell and electrode designs for producing electricity from microbial degradation. Biotechnol Bioeng 81: 348-355.

Pham TH, Rabaey K, Aelterman P, Clauwaert P, De Schamphelaire L, Boon N et al. (2006). Microbial fuel cells in relation to conventional anaerobic digestion technology. Eng Life Sci 6: 285-292.

Rabaey K, Boon N, Höfte M, Verstraete W. (2005a). Microbial phenazine production enhances electron transfer in biofuel cells. Environ Sci Technol 39: 3401-3408.

Rabaey K, Boon N, Siciliano SD, Verhaege M, Verstraete W. (2004). Biofuel cells select for microbial consortia that self-mediate electron transfer. Appl Environ Microbiol 70: $5373-5382$.

Rabaey K, Clauwaert P, Aelterman P, Verstraete W. (2005b). Tubular microbial fuel cells for efficient electricity generation. Environ Sci Technol 39: 8077-8082.

Rabaey K, Lissens G, Siciliano SD, Verstraete W. (2003). A microbial fuel cell capable of converting glucose to electricity at high rate and efficiency. Biotechnol Lett 25: 1531-1535.

Rabaey K, Van de Sompel K, Maignien L, Boon N, Aelterman P, Clauwaert P et al. (2006). Microbial fuel cells for sulfide removal. Environ Sci Technol 40: 5218-5224.

Rabaey K, Verstraete W. (2005). Microbial fuel cells: novel biotechnology for energy generation. Trends Biotechnol 23: 291-298.

Rao JR, Richter GJ, Vonsturm F, Weidlich E. (1976). Performance of glucose electrodes and characteristics of different biofuel cell constructions. Bioelectrochem Bioenerg 3: 139-150.

Reguera G, McCarthy KD, Mehta T, Nicoll JS, Tuominen MT, Lovley DR. (2005). Extracellular electron transfer via microbial nanowires. Nature 435: 1098-1101.
Reguera G, Nevin KP, Nicoll JS, Covalla SF, Woodard TL, Lovley DR. (2006a). Biofilm and nanowire production leads to increased current in Geobacter sulfurreducens fuel cells. Appl Environ Microbiol 72: 7345-7348.

Reguera G, Pollina RB, Nicoll JS, Lovley DR. (2006b). Possible non-conductive role of Geobacter sulfurreducens pili nanowires in biofilm formation. J Bacteriol 189: 2125-2127.

Roller SD, Bennetto HP, Delaney GM, Mason JR, Stirling JL, Thurston CF. (1984). Electron-transfer coupling in microbial fuel-cells. 1. Comparison of redox-mediator reduction rates and respiratory rates of bacteria. $J$ Chem Technol Biotechnol B-Biotechnol 34: 3-12.

Rozendal RA, Hamelers HVM, Euverink GJW, Metz SJ, Buisman CJN. (2006). Principle and perspectives of hydrogen production through biocatalyzed electrolysis. Int J Hydrogen Energy 31: 1632-1640.

Ryckelynck N, Stecher HA, Reimers CE. (2005). Understanding the anodic mechanism of a seafloor fuel cell: Interactions between geochemistry and microbial activity. Biogeochemistry 76: 113-139.

Sakakibara Y, Kuroda M. (1993). Electric prompting and control of denitrification. Biotechnol Bioeng 42: 535-537.

Salomons W, Rooij NM, Kerdijk H, Bril J. (1987). Sediments as a source for contaminants? Hydrobiologia 149: 13-30.

Straub KL, Schink B. (2004). Ferrihydrite-dependent growth of Sulfurospirillum deleyianum through electron transfer via sulfur cycling. Appl Environ Microbiol 70: 5744-5749.

Thrash JC, VanTrump JI, Weber KA, Miller E, Achenbach LA, Coates JD. (2007). Electrochemical stimulation of microbial perchlorate reduction. Environ Sci Technol 41: 1740-1746.

Supplementary Information accompanies the paper on The ISME Journal website (http://www.nature.com/ismej) 